\title{
A multi-objective optimization model for energy-efficiency building envelope retrofitting plan with rooftop PV system installation and maintenance
}

\author{
Yuling Fan*, Xiaohua Xia \\ Department of Electrical, Electronic and Computer Engineering, University of Pretoria, Pretoria 0002, South Africa
}

\begin{abstract}
Retrofitting existing buildings with energy-efficient facilities is an effective method to improve their energy efficiency, especially for old buildings. A multi-objective optimization model for building envelope retrofitting is presented. Envelope components including windows, external walls and roofs are considered to be retrofitted. Installation of a rooftop solar panel system is also taken into consideration in this study. Rooftop solar panels are modeled with their degradation and a maintenance scheme is studied for sustainability of energy and its long-term effect on the retrofitting plan. The purpose is to make the best use of financial investment to maximize energy savings and economic benefits. In particular, net present value, the payback period and energy savings are taken as the main performance indicators of the retrofitting plan. The multi-objective optimization problem is formulated as a non-linear integer programming problem and solved by a weighted sum method. Results of applying the designed retrofitting plan to a 50-year-old building consisting of 66 apartments demonstrated the effectiveness of the proposed model.
\end{abstract}

Keywords: Building envelope retrofit, multi-objective optimization, rooftop PV system, economic analysis.

\section{Introduction}

The building sector bears a large responsibility for energy consumption as it accounts for about $32 \%$ of the total final energy consumption globally and some $40 \%$ of that in the European Union [1]. Although future buildings can be designed to reduce their energy consumption, existing buildings still make up the largest portion of buildings in service [2]. Therefore, making existing buildings more energy-efficient is an important and economically beneficial way to save energy. In particular, $50 \%$ of a general purpose building's total energy consumption is dissipated through its envelope [3]. Improving the energy efficiency of building envelopes is thus a priority method to improve energy efficiency and to reduce energy demand for the building sector. As the performance of building envelope components degrades on account of environmental conditions over time, retrofitting more efficient and/or new ones is an effective way of achieving efficiency improvement $[2,4,5,6]$. In addition, necessary maintenance plays a key role in maintaining the energy performance of the retrofitted items in

\footnotetext{
${ }^{*}$ Corresponding author. Email: ylfan.up@gmail.com.
}

the long run $[6,7,8]$. Both the maintenance cost and performance degradation of the retrofitted items affect the financial viability of a retrofitting plan $[2,6]$. It is, therefore, essential to take into account these factors at the planning stage of the retrofitting.

Limited research has been done concerning the envelope retrofitting of buildings. Studies taking into account maintenance in the retrofitting plan are even scarcer. Reported literature on the building envelope mainly focused on improvement of envelope design and materials, and their applications. For instance, studies on the thermal performance of building envelopes were reported in [9],[10] and [11], etc. These studies focused mainly on investigating the effects of the thermal properties of the building envelope component on the building's energy consumption by means of either experimental or simulation methods. Similar studies investigating the influences of the thermal performance of wall materials applied in net-zero buildings were also published in recent years, such as $[12,13]$. The modeling and constructional design of building envelopes were studied in [14, $15,16,17,18]$. These studies mainly tried to identify the best envelope design, making use of different 
structures to achieve better thermal insulation, taking advantage of energy modeling techniques. Research on the evaluation of different energy-saving materials and structures for use in building envelopes was also found in literature [19, 20, 21]. Lastly, some studies on the composition and structure of walls [22, $23,24]$ and the owners' perception of the adoption of building envelope energy-efficient measures in Swedish [25] houses were studied.

While all of these studies add value to the energyi efficiency improvement of building envelopes, there is a gap between technology development and its mar ket uptake. It is therefore crucial to investigate the impacts of newly developed technologies and their en ergy and financial implications when they are applied to real world buildings. This is the main motiva tion of this paper, namely to optimally design a fi nancially appealing retrofitting plan making use of energy-efficient technologies to improve the energy performance of existing buildings.

In this regard, a few papers reporting attempts to design an optimal retrofitting plan were found in the literature [26] [27]. While these papers have made good contributions to research into retrofitting building envelopes, it is observed that some important performance indicators of a retrofitting plan, as well as the performance degradation of retrofitted items, were not considered in those studies. The plans ob tained may be financially infeasible because of overestimation of savings potential of the retrofitting or be cause the financial indicators of the retrofitting plans are not accounted for in the optimization problem formulated.

To be specific, the thermal performance of facilities and materials degrade over time and so do energy savings achieved by the retrofitting. This overestimation usually results in hesitation on the part of the project investors.

In order to work out a retrofitting plan that can make full use of or attract investment from decision makers, it is important to estimate the energy saving and financial benefits accurately. This requires performance degradation of the retrofitted items to be taken into account by the retrofitting plan. In case there is a sustainability requirement of the retrofittingi project, such as required by the clean development mechanism projects [28, 29], the maintenance cost ofi the project must also be considered. In addition, the thermal performance of the building, such as thermal comfort, after retrofitting must be guaranteed for the benefit of the occupants. In view of the aforementioned facts, the primary goal of this study is to optimally determine a retrofitting plan taking into account energy savings, thermal performance and financial indicators such that the plan contributes to energy efficiency improvement of the building in a financially viable manner. In particular, performance degradation of the retrofitted facilities and the corresponding maintenance are taken into account in the retrofitting plan to obtain a more accurate estimation of energy savings and financial benefits.

The main contribution of this paper is that a multi-objective optimization model for building enelope retrofitting, which takes facility performance egradation and economic feasibility of the retrofitting nto account, is formulated from the perspective of deision makers. In existing studies, no economic analysis and optimization of the multi-objective retrofitting problem were done to help decision makers. Therefore, the model formulated in this study takes into account both energy savings and economic benefits of the retrofitting investment, which are critical indicators of an investment for decision makers. In particular, the net present value (NPV) and payback period are directly considered and optimized by the presented model to not only pursuit for an economically beneficial retrofitting plan, but also enable the decision maker to make an informed decision. In addition, the optimal selection and sizing of a rooftop solar panel power supply system are formulated as an integral part of the retrofitting planning model to reduce usage of electricity produced from fossil fuels in view of the rich solar radiation in South Africa. Lastly, this model also considers the maintenance costs of the retrofitted items over the project period, which are usually ignored in the existing literature, to obtain an accurate estimation of the savings potential and consequently an accurate payback period estimation for the decision maker.

In this study, it is considered to replace windows with better alternatives and to install insulation materials for external walls and the roof. A rooftop solar panel power supply system is to be installed during building envelope retrofitting. The new windows, wall and roof insulation materials are used to reduce heat transfer and the solar panel power supply system is intended to reduce power demand from the grid and protect the building from unpredictable power outages, consequently, contribute to better life quality for the occupants [30] and reduced $\mathrm{CO}_{2}$ emission [31]. 
Although other technologies, such as district heating/cooling, can be also included in the model presented, they are not directly considered in this study because of their availability in South Africa's local environment. In particular, South Africa is a country with rich solar energy resource, which makes PV installation favorable, and no infrastructure of district heating/cooling system. Solar water heating system was not considered because electric geysers are the majority of water heaters used in existing buildings in South Africa. Therefore, using PV instead of solar water heating system is preferable as it is able to make use of these existing heaters. The model chooses the best candidate item from each group of available alternatives for the building envelope retrofitting and determines the optimal size of the solar panel system to be installed. The primary goal of the optimization model is to answer the question: which alternatives are to be used for retrofitting and what size should the solar panel power supply system be to ensure that the retrofitting plan is optimal in terms of both energy savings and financial benefits?

To account for the sustainability requirement of certain projects, the performance degradation and corresponding maintenance of the solar panel system installed are built into the retrofitting plan model. At this stage, a scheduled full maintenance plan at fixed intervals is considered according to the general methodology described in [32] and [6]. It is planned to include maintenance of other components, such as the insulation materials, and the design of an optimal maintenance plan in a future study.

The remainder of this paper includes four parts. Modeling of the solar power system and energy consumption of the building are presented in Section 2 . Formulation of the retrofitting plan into an optimization problem is elaborated on in Section 3. After that, a case study with results analysis is provided in Section 4. A conclusion is drawn in Section 5.

\section{Problem modeling}

Energy producing and consuming processes that are relevant to the optimal retrofitting plan of building envelopes are modeled. The solar panel power supply system is modeled first in order to determine its energy contribution to the building. In addition, the failure of the solar panels, which results in the performance degradation of the power supply system must be characterized in order to obtain an accurate estimation of energy generation of the system through the project's lifespan. The corresponding maintenance plan for the solar system is also presented here to facilitate the design of a complete retrofitting plan.

For the practical application studied, it was found that the available rooftop area of the building limits the installation of solar panels. In particular, it was found that the maximum power produced by solar panels would be less than the minimum demand of the building even if the best solar panels were installed over the complete rooftop area of the building. Therefore, it is not necessary to consider an energy storage system for the particular solar power system. The corresponding maintenance cost of the storage system is thus not considered in the problem formulation.

\subsection{Degradation models of solar panels}

Although the solar panel power system is often described as very reliable system with about 25 years' output power warranty, its performance still degrades inevitably over time as the total effective power output of the solar panel power supply system is affected by the number of surviving solar panels at a certain time [33]. This degradation results in more energy cost for the building owing to an increase in power purchase from the grid, which inversely affects the sustainability of the retrofitting project. Therefore, the population degradation of solar panels in the power supply system is important and is considered in this study. According to existing research [34], the population degradation model of solar panels can be described by the Weibull distribution, which is the most popular method used to analyze reliability and life distribution. The general form of population degradation of solar panels can be estimated by the following equation [34]:

$$
R(t)=e^{-\left(\frac{t}{\varphi}\right)^{3}},
$$

where $R(t)$ represents the survival rate of solar panels at time $t, \varphi$ is a scale parameter. Hence, with a given $\mathrm{E}$, the lifespan of solar panels, the value of the coefficient $\varphi$ can be obtained by solving the following equation $[2,6]$ :

$$
R(\mathrm{E})=0.5 \text {. }
$$

Some other factors that affect the overall output of the solar panel power supply system, such as dust on 
the glass, etc., are not considered in this study, as they are much easier to deal with.

Making use of equation (1), the number of solar panels installed at the beginning of the retrofitting project that still works properly at the end of the $t$-th year can be obtained by the following equation:

$$
D(t)=N_{p v}^{0} R(t)
$$

in which $N_{p v}^{0}$ is the number of solar panels installed at the beginning of retrofitting.

In view of solar panel breakages, a full maintenance plan at fixed time intervals is adopted for the installed solar panels. This is described as follows:

$$
M(t)=\left\{\begin{array}{l}
N_{p v}^{0}-D(t), \text { if } t=k T_{s} \\
0, \text { otherwise }
\end{array}\right.
$$

where $k$ is a positive integer, $M(t)$ is the number of panels installed during maintenance and $T_{s}$ is the maintenance interval, which means that maintenance activity happens every $T_{s}$ years. During the maintenance process, the failed solar panels are all replaced together, thus the population size will be restored to $N_{p v}^{0}$ after maintenance. Therefore, $N_{p v}(t+1)$, the number of solar panels that work properly at the beginning of year $t+1$, is determined by:

$$
N_{p v}(t+1)=D(t)+M(t) .
$$

\subsection{Energy produced by solar panels}

The energy produced by solar panels chosen by the retrofitting plan must be determined. Knowing the population degradation together with the maintenance strategy detailed in Section 2.1, the energy produced by the installed solar panel power supply system in the $t$-th year, $Q_{p v}(t)(\mathrm{kWh} /$ year $)$, can be calculated by the following equation [35, 36, 37, 38]:

$$
Q_{p v}(t)=\sum_{l=1}^{L}\left(x_{l}^{p v} \zeta_{l}\right) \sum_{l=1}^{L}\left(x_{l}^{p v} A_{l}^{p v}\right) I_{p v} \zeta_{p} D(t),
$$

where $\zeta_{l}$ is the efficiency of the $l$-th type solar panel, $A_{l}^{p v}$ is the area of one solar panel of type $l\left(\mathrm{~m}^{2}\right)$ $I_{p v}$ is solar irradiation $\left(\mathrm{kWh} / \mathrm{m}^{2}\right.$ year $), \zeta_{p}$ is the average solar to electrical power conversion efficiency taking into account losses due to temperature, etc. $x_{l}^{p v}$ denotes whether the $l$-th type of the solar panels is chosen for the retrofitting, i.e., when $x_{l}^{p v}=1$, it is chosen to be installed during the retrofitting, while it 0 is not chosen when $x_{l}^{p v}=0$.

\subsection{Energy consumption of space heating}

After the solar panel power supply system has been modeled, the main energy consumers in a building must be modeled to determine the energy balance of the building. In a general building, the energy consumption for space heating $Q_{\text {heat }}(\mathrm{kWh} /$ year $)$ is calculated by the following equation [39] [40]:

$$
Q_{\text {heat }}=Q_{e x t}+Q_{e n u}-Q_{p t}+Q_{v}-Q_{g u},
$$

in which

$$
\begin{aligned}
& Q_{\text {ext }}=0.024 D D \cdot B L C_{\text {ext }}, \\
& Q_{\text {enu }}=0.024 D D \cdot U_{n} \cdot A_{i}, \\
& Q_{p t}=0.024 D D \cdot \Psi \cdot B \\
& Q_{v}=0.024 D D\left(0.34 A C H \cdot A_{p} \cdot P_{d}\right), \\
& Q_{g u}=\mu\left[\left(M \cdot G_{\text {south }} \sum_{i=1}^{I} x_{i}^{\text {win }} \delta_{i} \sum_{i=1}^{4} Z_{i} \cdot A_{e, i}\right)\right. \\
& \left.+\left(0.72 A_{p} \cdot M \cdot q_{i}\right)\right], \\
& B L C_{\text {ext }}=A_{\text {win }} \sum_{i=1}^{I} U_{i} x_{i}^{\text {win }}+A_{\text {wall }} \sum_{j=1}^{J} x_{j}^{\text {wall }} . \\
& \frac{U_{w} \lambda_{j}}{U_{w} d_{j}+\lambda_{j}}+A_{\text {roof }} \sum_{k=1}^{K} x_{k}^{\text {roof }} \frac{U_{r} \lambda_{k}}{U_{r} d_{k}+\lambda_{k}} .
\end{aligned}
$$

In equations (7)-(13), $Q_{\text {ext }}$ is heat loss through zones in contact with the outdoor environment, including walls, glazing, roofs and pavements (kWh/year). $Q_{e n u}$ is heat loss through zones in contact with non-useful spaces, including walls, glazing, roofs and pavements (kWh/year). $Q_{p t}$ is heat loss through linear thermal bridges (kWh/year). $Q_{v}$ is heat loss through fresh air flow (kWh/year). $Q_{g u}$ is useful heat gains (kWh/year). $D D$ is degree-days $\left({ }^{\circ} \mathrm{C} /\right.$ day $) . B L C_{\text {ext }}$ is the building load coefficient $\left(\mathrm{W} /{ }^{\circ} \mathrm{C}\right) . U_{n}$ is the thermal transmission coefficient in non-useful space $\left(\mathrm{W} / \mathrm{m}^{2 \circ} \mathrm{C}\right) . A_{i}$ is the area of non-heated spaces $\left(\mathrm{m}^{2}\right)$. $\Psi$ is linear heat flux transmission $\left(\mathrm{W} /{ }^{\circ} \mathrm{C}\right) . B$ is the interior length of the contact between the floor or wall interior linear perimeter and soil or thermal bridge interior length $(\mathrm{m}) . A C H$ is air changes per hour $\left(\mathrm{h}^{-1}\right) . A_{p}$ is the net floor area $\left(\mathrm{m}^{2}\right) . P_{d}$ is the height from floor to ceiling $(\mathrm{m}) \cdot x_{i}^{\text {win }}$ denotes the state of the $i$-th alternative of the windows, i.e., when $x_{i}^{\text {win }}=1$, it is chosen for the retrofitting, while if $x_{i}^{\text {win }}=0$, it is not. The same type of variables, such as $x_{j}^{\text {wall }}$ and $x_{k}^{r o o f}$, are defined for wall insulation materials and roof insulation materials. They denote whether the 
$j$-th alternative of the external wall insulation materials and the $k$-th alternative of the roof insulation materials are chosen for retrofitting. $\mu$ is the heat gains utilization factor. $M$ is the heating season duration (months). $q_{i}$ is internal gains $\left(\mathrm{W} / \mathrm{m}^{2}\right) . G_{\text {south }}$ is the average solar energy that reaches a south-oriented vertical surface $\left(\mathrm{kWh} / \mathrm{m}^{2}\right) . \quad \delta_{i}$ is effective solar energy transmittance of the $i$-th type window. $Z_{i}$ is the orientation coefficient for different facades. $A_{e}$ is the effective glazing solar radiation collector area for the windows with different orientations $\left(\mathrm{m}^{2}\right) . A_{\text {win }}$, $A_{\text {wall }}$ and $A_{\text {roof }}$ are the surface areas of windows, exterior walls and the roof, respectively $\left(\mathrm{m}^{2}\right) . U_{i}$ is the thermal transmission of the $i$-th type of windows $\left(\mathrm{W} / \mathrm{m}^{2 \circ} \mathrm{C}\right) . U_{w}$ and $U_{r}$ are the thermal transmittance of walls and roof before retrofitting, respectively $\left(\mathrm{W} / \mathrm{m}^{2 \circ} \mathrm{C}\right) . d_{j}$ and $d_{k}$ are the thickness of the $j$ th type of external wall insulation materials and $k$-th type of roof insulation materials, respectively $(\mathrm{m}) . \lambda_{j}$ and $\lambda_{k}$ are the thermal conductivity of the $j$-th type of external wall insulation materials and $k$-th type of roof insulation materials, respectively $\left(\mathrm{W} / \mathrm{m}^{\circ} \mathrm{C}\right)$.

\subsection{Energy consumption of space cooling}

The energy consumption for space cooling in a building $Q_{\text {cool }}$ (kWh/year) is calculated by the following equation [39]:

$$
Q_{\text {cool }}=(1-\mu)\left(Q_{g u}+Q_{e}+Q_{t}+Q_{i}\right),
$$

in which

$$
\begin{aligned}
Q_{e} & =B L C_{e x t}\left[2.928\left(\theta_{m}-25\right)+\left(\alpha \frac{I_{r}}{25}\right)\right], \\
Q_{t} & =2.928\left(0.34 A C H \cdot A_{p} \cdot P_{d}\right)\left(\theta_{m}-25\right), \\
Q_{i} & =2.928 A_{p} \cdot q_{i} .
\end{aligned}
$$

In equations (14)-(15), $Q_{e}, Q_{t}$ and $Q_{i}$ are, respectively, heat gain through the envelope, heat transfer due to infiltration and internal heat gains $(\mathrm{kWh} /$ year). $\theta_{m}$ is the average outdoor temperature in the cooling season $\left({ }^{\circ} \mathrm{C}\right) . \alpha$ is the exterior envelope solar radiation absorption coefficient. $I_{r}$ the is average solar radiation intensity $\left(\mathrm{W} / \mathrm{m}^{2}\right)$.

\subsection{Energy consumption of water heating}

The energy consumption for water heating in a building $Q_{\text {water }}$ (kWh/year) is calculated by the following equation [39]:

$$
Q_{\text {water }}=0.081 M_{a} \cdot \frac{n_{d}}{\sigma},
$$

where $M_{a}$ is the average daily water consumption $(\mathrm{kWh}), n_{d}$ is the number of days when domestic water heating occurs, $\sigma$ is the domestic water heating system efficiency.

\section{Optimization}

The plan of retrofitting considering maintenance determines the set of items to be retrofitted. As stated earlier, windows, external wall insulation materials and roof insulation materials are considered for retrofitting and a rooftop solar panel power supply system is considered to be installed in this study. The corresponding optimization problem is described in the following sections.

\subsection{Decision variables}

Assume that there are $I, J, K, L$ alternatives of the four items for the retrofitting. Let $X^{\text {win }}=$ $\left(x_{1}^{\text {win }}, \ldots, x_{I}^{\text {win }}\right), X^{\text {wall }}=\left(x_{1}^{\text {wall }}, \ldots, x_{J}^{\text {wall }}\right), X^{\text {roof }}=$ $\left(x_{1}^{r o o f}, \ldots, x_{K}^{r o o f}\right), X^{p v}=\left(x_{1}^{p v}, \ldots, x_{L}^{p v}\right)$. The decision variable of the retrofitting planning problem is then given by:

$$
X=\left(X^{\text {win }}, X^{\text {wall }}, X^{\text {roof }}, X^{p v}, N_{p v}^{0}\right) .
$$

\subsection{Objectives}

This study aims at maximizing energy savings and promoting implementation of the formulated plan by means of looking at the financial indicators of the plan. Therefore, the retrofitting plan is formulated into an optimisation problem maximizing energy savings and NPV and minimizing the payback period of the investment. Thus a multi-objective optimization problem is formulated. Usually, the solution of multiobjective optimisation problems constitutes a Pareto front which represents a set of solutions. Finding the complete Pareto front is computationally intense and even impossible in some cases. Even if the complete Pareto front could be found, the decision maker would then be required to pick a solution from the Pareto front. In other words, the final solution of the problem requires human intelligence. In this study, we make use of a weighted sum method [41], which is popularly used to convert a multi-objective optimisation problem into a single objective optimisation problem. While this method cannot guarantee to find the complete Pareto front, it is a useful tool that can find a solution to the original multi-objective problem with specified weighting factors, which are usually 
selected carefully according to the trade-offs made among the objectives. The weighted sum method gives decision managers a way to interface with the optimisation and achieve the desired performance of the retrofitting plan by tuning the weighting factors. Using the weighted sum method, the multi-objective problem is converted into a single objective optimisation problem with the following objective function:

$$
J=-w_{1} \frac{E S_{t o t}}{\overline{E S}_{t o t}}-w_{2} \frac{N P V}{N P V}+w_{3} \frac{T_{p}}{\bar{T}_{p}},
$$

where $w_{1}, w_{2}$ and $w_{3}$ are positive weights, $E S_{t o t}$ is the total energy savings after the retrofitting considering facility performance degradation over time and maintenance actions during the period $[0, T](\mathrm{kWh})$, $T_{p}$ is the payback period (months). In equation (17), $\overline{E S}_{t o t}, \overline{N P V}$ and $\bar{T}_{p}$ are the maximum values of the $E S_{t o t}, N P V$ and $T_{p}$, respectively, used to standardize the objective function for the convenience of tuning the weighting factors. Calculations of $E S_{t o t}, N P V$ and $T_{p}$ are detailed in the following subsections.

\subsubsection{Energy savings}

The total energy savings after implementing the retrofitting plan considering maintenance during a time period $[0, T]$ is calculated by the following equation:

$$
E S_{\text {tot }}=E S_{\text {pre }}-E S_{\text {post }}=\sum_{t=1}^{T} E S(t),
$$

where $E S_{\text {pre }}$ and $E S_{\text {post }}$ are the total energy con-3з2 sumption before and after retrofitting, respectively $y_{333}$ $(\mathrm{kWh}), E S(t)$ is the energy savings in the $t$-th year $(\mathrm{kWh})$.

\subsubsection{Net present value}

NPV is the difference between the present values of cash inflows and cash outflows over a period of time. The NPV method is usually used in capital budgeting to analyze the profitability of a projected investment or project. In this study, the NPV method is used to evaluate the overall value of the retrofitting plan considering maintenance. It can be determined with the discount rate $d$ by the following equation:

$$
N P V=\sum_{t=1}^{T} \frac{E S(t) p(t)-C_{m}(t)}{(1+d)^{t}}-C_{r},
$$

where

$$
\begin{aligned}
E S(t)= & \Delta Q_{\text {heat }}+\Delta Q_{\text {cool }}+\Delta Q_{\text {water }}+Q_{p v}(t), \\
C_{m}(t)= & M(t) \sum_{l=1}^{L} x_{l}^{p v} C_{m_{l}}^{p v}, \\
C_{r}= & A_{\text {win }} \sum_{i=1}^{I} x_{i}^{\text {win }} C_{i}^{\text {win }}+A_{\text {wall }} \sum_{j=1}^{J} x_{j}^{\text {wall }} C_{j}^{\text {wall }} \\
& +A_{\text {roof }} \sum_{k=1}^{K} x_{k}^{\text {roof }} C_{k}^{\text {roof }}+N_{p v}^{0} \sum_{l=1}^{L} x_{l}^{p v} C_{l}^{p v} .
\end{aligned}
$$

In equations (19)-(22), $p(t)$ is the electricity price at time $t(\$ / \mathrm{kWh}), C_{m}(t)$ is the maintenance cost for the solar panel power supply system in the $t$-th year $(\$)$, $C_{r}$ is the cost of building envelope retrofitting (\$), $d$ is the discount rate, $\Delta Q_{\text {heat }}, \Delta Q_{\text {cool }}$ and $\Delta Q_{\text {water }}$ are the difference of the energy consumption before and after the retrofitting for space heating, space cooling and water heating, respectively, in the $t$-th year $(\mathrm{kWh}), C_{m_{l}}^{p v}$ is the unit maintenance cost of the $l$ th type solar panel $(\$), C_{i}^{\text {win }}, C_{j}^{\text {wall }}$ and $C_{k}^{\text {roof }}$ are the cost of the $i$-th type of windows, $j$-th type of external wall insulation materials and the $k$-th type of roof insulation materials, respectively $\left(\$ / \mathrm{m}^{2}\right)$. $C_{l}^{p v}$ and $A_{l}^{p v}$ are the unit cost $(\$)$ and area $\left(\mathrm{m}^{2}\right)$ of the $l$-th type of solar panels, respectively. From equation (19) and (21), it can be observed that this formulation explicitly builds the maintenance cost of the project into the optimization problem, which yields more accurate estimation of the project cost and performance during the evaluation period.

\subsubsection{Payback period}

The discounted payback period is an important indicator of how quickly an investment repays its capital cost considering the time value of money. This is usually an indicator decision makers look at when comparing different investment options. It is defined as the time point after which NPV turns and stays non-negative and can be obtained by the following equation:

$$
T_{p}=N+\frac{C_{f_{a}}}{C_{f_{b}}},
$$

where $N$ is the last month with a negative cumulative cash flow, $C_{f_{a}}$ is the absolute value of the cumulative cash flow at the end of the $N$-th month $(\$), C_{f_{b}}$ is the total cash flow during the $(N+1)$-th month $(\$)$. 
Table 1: Information on windows

\begin{tabular}{lllll}
\hline$i$ & Description & $U_{i}\left(\mathrm{~W} / \mathrm{m}^{\circ} \mathrm{C}\right)$ & $\delta_{i}(\%)$ & $C_{i}^{\text {win }}\left(\$ / \mathrm{m}^{2}\right)$ \\
\hline 1 & Single glazing, typical glazing & 5.1 & 85 & 43.91 \\
2 & 2bl glazing, without thermal break, uncoated air-filled metallic frame 4-12-4 & 2.8 & 75 & 50.79 \\
3 & 2bl glazing, without thermal break, uncoated air-filled metallic frame 4-16-4 & 2.7 & 51.94 \\
4 & 2bl glazing, low-e window (with thermal break) coated air-filled metallic frame & 1.6 & 75 & 71.79 \\
& 4-12-4 NEUTRALUX & & \multirow{2}{*}{174.62} \\
5 & 2bl glazing, window air-filled metallic frame 6-12-4 SOLARLUX Supernatural & 1.6 & 44 \\
& 70/40 Temprado & & \\
\hline
\end{tabular}

\subsection{Constraints}

Economic and physical constraints of the problem are given in the following equations:

$$
\begin{aligned}
& C_{\text {tot }} \leq \beta, \\
& \sum_{l=1}^{L} x_{l}^{p v} A_{l}^{p v} N_{p v} \leq A_{e f f}, \\
& \begin{cases}\sum_{i=1}^{I} x_{i}^{\text {win }}=1 & \text { for } x_{i}^{\text {win }} \in\{0,1\}, \forall i \in\{1,2 \cdots, I\} \\
\sum_{j=1}^{J} x_{j}^{\text {wall }}=1 & \text { for } x_{j}^{\text {wall }} \in\{0,1\}, \forall j \in\{1,2 \cdots, J\} \\
\sum_{k=1}^{K} x_{k}^{\text {roof }}=1 & \text { for } x_{k}^{\text {roof }} \in\{0,1\}, \forall k \in\{1,2 \cdots, K\} \\
\sum_{l=1}^{L} x_{l}^{p v}=1 & \text { for } x_{l}^{p v} \in\{0,1\}, \forall l \in\{1,2 \cdots, L\},\end{cases}
\end{aligned}
$$

where $C_{t o t}$ is the total cost of the building envelope retrofitting considering maintenance during a time period $[0, T]$,

$$
C_{t o t}=C_{r}+\sum_{t=1}^{T} C_{m}(t),
$$

and $\beta$ is the budget allocated for the project.

Inequalities (24) and (25) mean that the total cost of the building envelope retrofitting considering maintenance should be less than the total investment and the area of the solar panel power supply system that is installed should be less than the effective and usable area of the roof $A_{\text {eff }}$, respectively. Equations in (26) ensure that only one alternative for each retrofitting category is chosen by the plan.

\section{Case study}

\subsection{Parameters}

The existing building used for the case study is a South African residential building facing southeast It was constructed 50 years ago and consists of 66

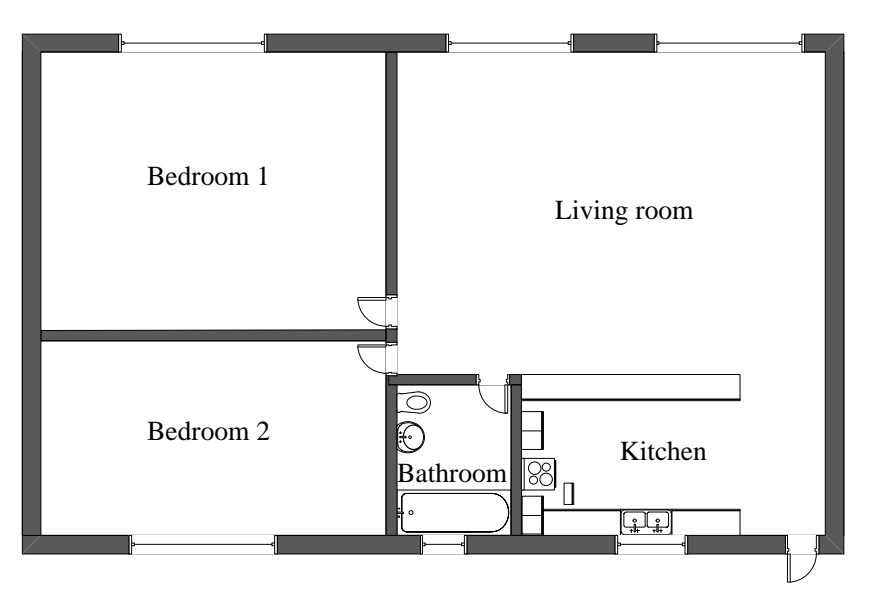

Figure 1: Structure of an apartment in the building under study

\begin{tabular}{lllll}
\multicolumn{6}{c}{ Table 2: Information on external wall insulation materials } \\
\hline$j$ & Description & $d_{j}(\mathrm{~m})$ & $\lambda_{j}\left(\mathrm{~W} / \mathrm{m}^{\circ} \mathrm{C}\right)$ & $C_{j}^{\text {wall }}\left(\$ / \mathrm{m}^{2}\right)$ \\
\hline 1 & Stone wool & 0.03 & 0.034 & 14.49 \\
2 & Glass wool & 0.05 & 0.038 & 16.32 \\
3 & EPS & 0.03 & 0.036 & 9.84 \\
4 & EPS & 0.07 & 0.036 & 13.45 \\
5 & EPS & 0.08 & 0.036 & 14.37 \\
6 & EPS & 0.08 & 0.033 & 21.10 \\
7 & EPS & 0.04 & 0.036 & 10.44 \\
8 & EPS & 0.06 & 0.036 & 12.32 \\
9 & SPF & 0.02 & 0.042 & 8.23 \\
10 & Cork & 0.01 & 0.040 & 3.93 \\
11 & Cork & 0.1 & 0.040 & 23.13 \\
12 & Cork & 0.15 & 0.040 & 34.70 \\
13 & Cork & 0.30 & 0.040 & 69.38 \\
\hline
\end{tabular}

apartments. The plan of each apartment is identical, with two bedrooms, one living space, a small kitchen and a bathroom, as shown in Fig. 1. Each apartment has a gross area of $70 \mathrm{~m}^{2}$ and a glazing area of 13.3 $\mathrm{m}^{2}$, of which $10.6 \mathrm{~m}^{2}$ faces north and $2.7 \mathrm{~m}^{2}$ faces south. Standard single glazing windows with wood frames were used. No thermal insulation for walls and roof was installed.

The retrofitting plan considered for this building is evaluated for the duration of $T=24$ years, considering the performance deterioration of materials. Economic parameters are considered in the study, 
given such a long project duration. To this effect, the rate of increase in the electricity price is considered to be constant during the evaluation period; this is $8 \%$, according to Eskom (the largest utility in South Africa). The discount rate involved in the calculation of NPV is assumed to be $9 \%$, which is recommended for South Africa [42]. The set temperatures for the HVAC systems of the apartments in heating seasons and cooling seasons are $20^{\circ} \mathrm{C}$ and $25^{\circ} \mathrm{C}$, respectively. Other parameters, such as solar radiation intensity for different orientation, heating season duration, degree-days, etc., are taken from the South African National Standards [43].

The plan considered five alternatives of windows, thirteen alternatives of external wall insulation materials, ten alternatives of roof insulation materials and seven alternatives of solar panels to choose from for the retrofitting. Details of these alternatives are listed in Tables 1-4, where EPS stands for expanded polystyrene and SPF stands for sprayed polyurethane foam.

Table 3: Information on roof insulation materials

\begin{tabular}{lllll}
\hline$k$ & Description & $d_{k}(\mathrm{~m})$ & $\lambda_{k}\left(\mathrm{~W} / \mathrm{m}^{\circ} \mathrm{C}\right)$ & $C_{k}^{\text {roof }}\left(\$ / \mathrm{m}^{2}\right)$ \\
\hline 1 & SPF & 0.020 & 0.042 & 8.23 \\
2 & EPS & 0.030 & 0.033 & 5.57 \\
3 & EPS & 0.040 & 0.033 & 7.22 \\
4 & EPS & 0.050 & 0.033 & 8.85 \\
5 & EPS & 0.060 & 0.033 & 10.49 \\
6 & EPS & 0.070 & 0.033 & 12.15 \\
7 & EPS & 0.080 & 0.033 & 13.79 \\
8 & EPS & 0.040 & 0.034 & 15.00 \\
9 & Stone wool & 0.065 & 0.037 & 31.78 \\
10 & Stone wool & 0.105 & 0.037 & 44.84 \\
\hline
\end{tabular}

Table 4: Information on solar panels

\begin{tabular}{lllll}
\hline$l$ & Description & $C_{l}^{p v}(\$)$ & $\zeta_{l}$ & $A_{l}^{p v}\left(\mathrm{~m}^{2}\right)$ \\
\hline 1 & STP255-20/WD & 900.78 & $15.7 \%$ & 1.627 \\
2 & YL190P-23B & 592.62 & $14.7 \%$ & 1.297 \\
3 & YL265C-30B & 942.30 & $16.3 \%$ & 1.624 \\
4 & CS6X-300P & 870.33 & $15.6 \%$ & 1.919 \\
5 & HSL60P6-PB-1-240B & 704.82 & $14.8 \%$ & 1.616 \\
6 & Sharp ND 245 Poly & 1023.12 & $14.9 \%$ & 1.642 \\
7 & SW 275 MONO & 1042.50 & $16.4 \%$ & 1.593 \\
\hline
\end{tabular}

In this study, the full maintenance policy is applied every $T_{s}=6$ years because about $20 \%$ of the solar panels installed will fail in six years after the retrofitting, according to the degradation model of solar panels in Section 2. That is to say, the maintenance for the solar panel power supply system happens every six years. During each maintenance ac-

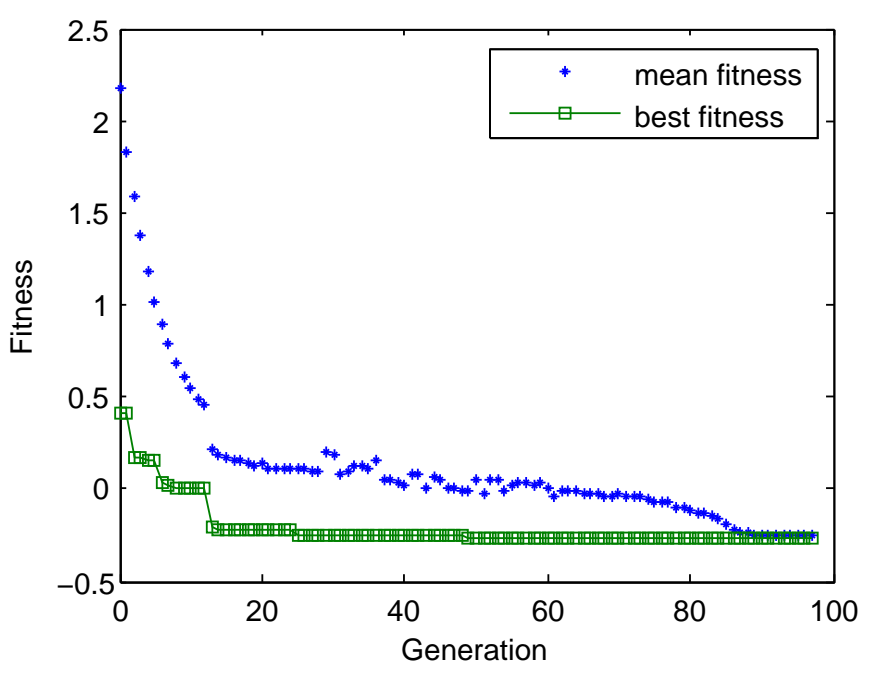

Figure 2: Convergence of the GA algorithm

tivity, the failed solar panels are all replaced together with new ones.

\subsection{Results analysis}

The multi-objective optimization problem formulated is essentially a mixed-integer programming problem. Conventional mathematical methods cannot be applied to solve this problem. Therefore, a genetic algorithm (GA) is employed in this study $[44,45]$. In the GA, the initial population size is set at 2000 , the crossover probability is set at 0.8 and the algorithm is set to terminate if the change of fitness of the best candidate is less than $1 \times 10^{-10}$.

Firstly, Fig. 2 is given to demonstrate that the GA algorithm will converge to a solution within acceptable numbers of generations. In this figure, both the fitness of the best individual in a generation and the average fitness of all individuals in a generation are plotted with respect to the number of generations. It is noted that the objective function is normalized with respect to its nominal value. It can be seen that they both decrease and the fitness of the best individual converges to a fixed value. Although GA cannot guarantee the global optimality of the solution found, this convergence is still important to show that the solution found by the GA is at least a local optimum. Essentially, because of the nature of the formulated problem, i.e. mixed-integer nonlinear programming problem, no mathematical method and artificial intelligence method can guarantee convergence to the global optimum.

The impact of different budgets on the solution is investigated secondly. Setting the weighting factors 
Table 5: $w_{1}=0.7, w_{2}=0.2$ and $w_{3}=0.1$

\begin{tabular}{|c|c|c|c|c|c|c|c|c|c|c|}
\hline$\beta(\$)$ & $C_{t o t}(\$)$ & $E S_{t o t}(\mathrm{kWh})$ & $E S_{t o t}(\%)$ & $\operatorname{NPV}(\$)$ & $T_{p}$ (month) & Win & Wall & Roof & Solar & $N_{p v}^{0}$ \\
\hline 80000 & 79663 & 6795741 & $36.95 \%$ & 732773 & 27 & 1 & 5 & 3 & 5 & 9 \\
\hline 100000 & 98224 & 7036293 & $38.25 \%$ & 742719 & 32 & 1 & 6 & 6 & 2 & 11 \\
\hline 120000 & 119296 & 7259845 & $39.47 \%$ & 747241 & 38 & 4 & 11 & 7 & 2 & 4 \\
\hline 140000 & 134273 & 7504273 & $40.80 \%$ & 766817 & 39 & 1 & 5 & 7 & 2 & 84 \\
\hline 160000 & 158078 & 7634215 & $41.50 \%$ & 759610 & 45 & 1 & 6 & 6 & 2 & 97 \\
\hline 180000 & 179511 & 7750310 & $42.14 \%$ & 755262 & 49 & 3 & 5 & 7 & 2 & 138 \\
\hline 200000 & 198594 & 8099689 & $44.04 \%$ & 778461 & 52 & 4 & 5 & 4 & 5 & 125 \\
\hline
\end{tabular}

to $w_{1}=0.7, w_{2}=0.2$ and $w_{3}=0.1$, the optimal solutions and the corresponding effects of the optimal retrofitting plans with different budgets are obtained and presented in Table 5. In Table 5, the number of solar panels is the number of solar panels to be installed at the beginning, which is optimally determined by the retrofitting plan. The columns Win, Wall, Roof and Solar reflect the choices of retrofitting plan among the different window, wall, roof and solar panel alternatives. For example, 1, 5, 3, 5 means that the combination of the first alternative of windows, the fifth alternative of external wall insulation materials, the third alternative of roof insulation materials and the fifth alternative of solar panels is the optimal option to retrofit the existing building. Energy savings, the NPV and payback period are also presented in the table, as these are the primary performance indicators of the retrofitting plan. In addition, the percentage energy savings with respect to the energy usage of the building before retrofitting is also shown in the table for easy comparison.

It can be seen from the table that the optimal retrofitting solution depends on the investment. It is observed that the optimal retrofitting plan is not simply to choose the cheapest options. With growing investments, the energy savings and payback period keep increasing while the NPV and the number of installed solar panels fluctuate.

It is interesting to note that the optimal number of solar panels to be installed decreased from 11 to 4 when the investment grew from $\$ 100000$ to $\$ 120000$. To explain this 'abnormality', one can find out that if the optimal choices of the alternatives in the budget of $\$ 100000$ (the first kind of window, the sixth kind of wall insulation material, the sixth kind of roof insulation material and the second kind of solar panel) were still used, the extra $\$ 20000$ budget would allow installation of 41 , instead of 4 , solar panels. This solution, however, results in a total energy saving o $7245317 \mathrm{kWh}$, which is less than $7259845 \mathrm{kWh}$, which was obtained by the optimal solution with the budget of $\$ 120000$. Since the weighting factors, $w_{1}, w_{2}$ and $w_{3}$, are tuned such that the optimization favors solutions with more energy savings, simply increasing the number of solar panels while keeping the choices of the different alternatives is an inferior solution. This demonstrates the ability of the model to search for a better solution with different budgets. Moreover, this shows that intuitive plans will not lead to the optimal utilization of the investment. The model presented is of great help to decision makers to develop an optimal retrofitting plan, considering different amounts of investments.

A similar phenomenon is observed when the budget is increased from $\$ 180000$ to $\$ 200000$ in Table 5 . This also indicates that when the budget is not enough for the retrofitting to select the best options of the envelope components/materials, it will prefer to improve the energy performance of the envelope over installing solar panels on the building. This is in line with the fact that roughly $50 \%$ of energy consumption of a building is dissipated by its envelope; improving energy efficiency of the envelope is, therefore, the first priority when investigating energy-efficient retrofitting of buildings.

The effectiveness of tuning of the weighting factors is studied thirdly. The optimal results with the same set of budgets used in Table 5, but different weighting factors are presented in Table 6 . The new set of weighting factors prioritizes the payback period minimization instead of maximizing energy savings from the retrofitting by imposing a larger $w_{3}=0.7$ and a smaller $w_{1}=0.1$ compared to the weighting factors used previously.

Comparing Table 5 and Table 6, one can easily found out that the payback periods shown in Table 6 are shorter than the corresponding values in Table 5 , verifying the effectiveness of tuning the weighting factors. Another interesting finding is observed when the investment grows from $\$ 160000$ to $\$ 180000$. The 
Table 6: $w_{1}=0.1, w_{2}=0.2$ and $w_{3}=0.7$

\begin{tabular}{|c|c|c|c|c|c|c|c|c|c|c|}
\hline$\beta(\$)$ & $C_{t o t}(\$)$ & $E S_{t o t}(\mathrm{kWh})$ & $E S_{t o t}(\%)$ & NPV (\$) & $T_{p}$ (month) & Win & Wall & Roof & Solar & $N_{p v}^{0}$ \\
\hline 80000 & 74472 & 6693658 & $36.39 \%$ & 724485 & 26 & 1 & 8 & 7 & 2 & 6 \\
\hline 100000 & 81114 & 6791717 & $36.92 \%$ & 731201 & 27 & 1 & 5 & 3 & 1 & 8 \\
\hline 120000 & 116070 & 7031982 & $38.23 \%$ & 726409 & 37 & 2 & 5 & 5 & 4 & 37 \\
\hline 140000 & 122515 & 7170607 & $38.98 \%$ & 737208 & 38 & 3 & 5 & 5 & 5 & 52 \\
\hline 160000 & 151036 & 7288412 & $39.62 \%$ & 726465 & 44 & 2 & 5 & 4 & 2 & 103 \\
\hline 180000 & 165476 & 7697435 & $41.85 \%$ & 757609 & 48 & 1 & 12 & 6 & 2 & 63 \\
\hline 200000 & 189586 & 7848263 & $42.67 \%$ & 757968 & 51 & 3 & 5 & 7 & 2 & 152 \\
\hline
\end{tabular}

envelope retrofitting combination is changed and the number of solar panels is reduced. Indeed, one can verify that if the same envelope retrofitting combination is used and the increased investment is solely used to increase the number of solar panels installed, one would get a retrofitting plan that has a payback period of 50 months, which is two months longer than that of the optimal plan.

Combining this finding with the observation discussed when the weighting factors were tuned to prioritize energy savings, one can conclude that improving the energy efficiency of the building's envelope should be the first priority when considering an energyefficient retrofitting plan of buildings if there is sufficient budget available. By choosing the optimal retrofitting options of the envelope components, one can get good energy savings together with a relatively short payback period of the investment. However, if the budget is limited, the model presented in this study will be of valuable help in determining the most favorable retrofit plan with given preferences on the performance indicators of the plan.

It is noted that, for the studied case, the max imum peak power output of the solar panel powe supply system installed by the retrofitting is $16.8 \mathrm{~kW}$ which is less than the measured minimum demand of the building, $57 \mathrm{~kW}$. This validates the assumption that no energy storage system is required for the solar power system, made at the beginning of Section 2 .

Lastly, a sensitivity analysis is performed to investigate the effects of parameter inaccuracies. In particular, the 9\% discount rate recommended in [42] could vary. Therefore, a $10 \%$ change in this recommended discounted rate is introduced, resulting in a discount rate of $8.1 \%$. This new discount rate is then applied and simulation with a budget of $\$ 80000$ is performed. The resulting changes in the performance indicators, namely energy savings, NPV and payback period, are shown in Fig. 3. To be specific, the so lution to the problem didn't change, which leads to
$0 \%$ change in energy savings. However, the NPV and payback period are affected by this decrease in the discount rate. As expected, the NPV increased by $11.9 \%$ (from $\$ 732773$ to $\$ 820093$ ) and the payback period decreased by $3.7 \%$ (from 27 to 26 months). It can be concluded that the energy savings achieved by the model are robust against the inaccuracies of the discount rate, while economic indicators are sensitive to discount rate changes.

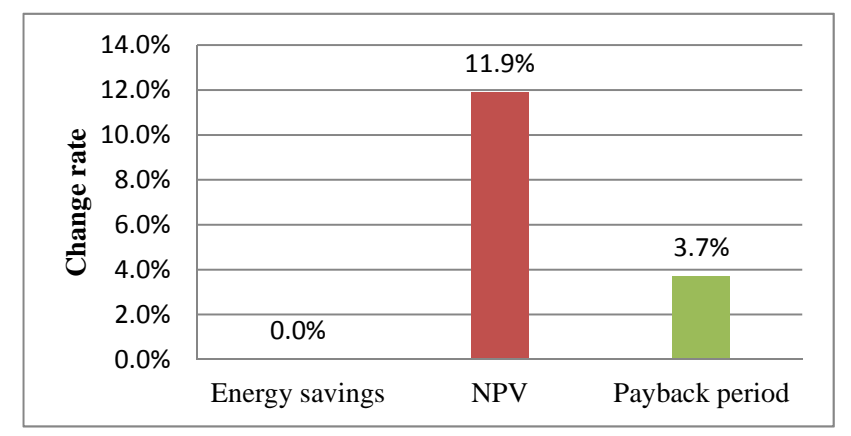

Figure 3: Sensitivity analysis of the discount rate

Overall, the results obtained in the case study verify the effectiveness of the proposed model in improving the energy efficiency of existing buildings, making the best use of investment by means of optimally determining a retrofitting plan for the building. In addition, the results obtained give explicit indicators that are of interest to potential investors and decision makers, such as NPV and payback period, taking into account the discounting factors and electricity price increase, which can be used by the decision makers to reach a more informed decision. More importantly, the results obtained can be helpful to clear hesitation of decision makers and attract more investment for similar building envelope retrofitting projects. Lastly, decision makers are provided with the option to adapt the weighting factors of the model presented in this study in order to obtain a desired retrofitting plan with their preferences over different performance indicators. For a given building retrofitting project, the 
presented model can be applied after an energy audit of the existing building to identify suitable retrofitting options that can be introduced to reduce the building's energy consumption. These parameters, including thermal properties, costs, etc. of the existing technologies and those of the identified options, can then be passed into the model developed to find an optimal retrofitting plan with given preferences on the energy and economic benefits specified by the weighting factors.

\section{Conclusion}

A multi-objective optimization model for a building envelope retrofitting plan is studied. The aim of this study is to improve the energy efficiency of existing buildings with a given budget to maximize the occupants' and investors' benefits. In the modeling process, the performance degradation and corresponding maintenance of a rooftop solar panel system are considered in order to improve the accuracy of estimated energy savings and economic benefits. Results of the optimization model can be used by decision makers to identify investment opportunities in building envelope retrofitting projects, as economic indicators, including NPV and payback period, are included in the results explicitly. The model also provides a con venient way for the decision makers to interact with the optimization by means of tuneable weighting fac tors to emphasize certain performance indicators. A case study carried out shows that, in a 24-year period the optimal retrofitting plan obtained for the building studied would yield promising energy savings with acceptable economic benefits for the investor. It is also concluded that retrofitting the envelope components should be given first priority when investigating energy efficiency improvement of existing buildings if sufficient budget is available. Future improvement of this study could include performance degradation of wall and roof insulation materials.

\section{References}

[1] Khatib, H.. IEA world energy outlook 2011: A comment Energy Policy 2012;48:737 - 743.

[2] Wang, B., Xia, X., Zhang, J.. A multi-objective optimization model for the life-cycle cost analysis and retrofitting planning of buildings. Energy and Buildings 2014;77:227 - 235 .

[3] Mavromatidis, L.E., Bykalyuk, A., Lequaya, H.. De velopment of polynomial regression models for composite dynamic envelopes thermal performance forecasting. Ap plied Energy 2013;104:379 - 391 .
[4] Wu, Z., Xia, X., Wang, B.. Improving building energy efficiency by multiobjective neighborhood field optimization. Energy and Buildings 2015;87:45 - 56 .

[5] Wu, Z., Wang, B., Xia, X.. Large-scale building energy efficiency retrofit: Concept, model and control. Energy 2016;109:456 - 465.

[6] Wang, B., Xia, X.. Optimal maintenance planning for building energy efficiency retrofitting from optimization and control system perspectives. Energy and Buildings 2015;96:299 - 308 .

[7] Wang, B., Xia, X.. Maintenance plan optimization in building retrofitting with interacting energy efficiency effects. In: Chinese Automation Congress, 2015. Wuhan, China; 2015, p. 1349-1354.

[8] Wang, B., Zhu, B., Xia, X.. Optimal control of maintenance instants and intensities in building energy efficiency retrofitting project. In: 54th IEEE Conference on Decision and Control. Osaka, Japan; 2015,.

[9] Huang, Y., Niu, J., Chung, T.. Study on performance of energy-efficient retrofitting measures on commercial building external walls in cooling-dominant cities. Applied Energy 2013;103:97 - 108.

[10] Yu, J., Tian, L., Xu, X., Wang, J.. Evaluation on energy and thermal performance for office building envelope in different climate zones of China. Energy and Buildings $2015 ; 86: 626-639$.

[11] Carlini, M., Allegrini, E., Zilli, D., Castellucci, S.. Simulating heat transfers through the building envelope: A useful tool in the economical assessment. Energy Procedia 2014;45:395 - 404 .

[12] Rehman, H.U.. Experimental performance evaluation of solid concrete and dry insulation materials for passive buildings in hot and humid climatic conditions. Applied Energy 2017;185:1585 - 1594 .

[13] Zhou, Z., Feng, L., Zhang, S., Wang, C., Chen, G., Du, T., et al. The operational performance of "net zero energy building": A study in China. Applied Energy 2016;177:716 $-728$.

[14] Koo, C., Park, S., Hong, T., Park, H.S.. An estimation model for the heating and cooling demand of a residential building with a different envelope design using the finite element method. Applied Energy 2014;115:205 - 215.

[15] Echenagucia, T.M., Capozzoli, A., Cascone, Y., Sassone, M.. The early design stage of a building envelope: Multiobjective search through heating, cooling and lighting energy performance analysis. Applied Energy 2015;154:577 -591 .

[16] Sang, X., Pan, W., Kumaraswamy, M.. Informing energy-efficient building envelope design decisions for Hong Kong. Energy Procedia 2014;62:123 - 131.

[17] Bastani, A., Haghighat, F., Kozinski, J.. Designing building envelope with PCM wallboards: Design tool development. Renewable and Sustainable Energy Reviews 2014;31:554 - 562.

[18] Karimpour, M., Belusko, M., Xing, K., Boland, J., Bruno, F.. Impact of climate change on the design of energy efficient residential building envelopes. Energy and Buildings 2015;87:142 - 154 .

[19] Revel, G.M., Martarelli, M., Emiliani, M., Celotti, L., Nadalini, R., Ferrari, A.D., et al. Cool products for building envelope - Part II: Experimental and numerical evaluation of thermal performances. Solar Energy 2014;105:780 
$-791$.

[20] Koci, J., Madera, J., Jerman, M., Cerny, R.. Computational assessment of thermal performance of contemporary ceramic blocks with complex internal geometry in building envelopes. Energy and Buildings 2015;99:61 - 66 .

[21] Zhang, T., Tan, Y., Yang, H., Zhang, X.. The application of air layers in building envelopes: A review. Applied Energy 2016;165:707 - 734 .

[22] Chwieduk, D.A.. Some aspects of energy efficient building envelope in high latitude countries. Energy Procedia 2014;57:1898 - 1907 .

[23] Lie, P., Zhu, N., Li, D., Shen, J., Cui, X.. Determination of the insulation thickness for the residential building envelope in severe cold areas. In: 2012 2nd Inter national Conference on Consumer Electronics, Communications and Networks. Yichang, China; 2012, p. 992-996.

[24] Gossard, D., Lartigue, B., Thellier, F.. Multi-objective optimization of a building envelope for thermal performance using genetic algorithms and artificial neural net work. Energy and Buildings 2013;67:253 - 260 .

[25] Nair, G., Gustavsson, L., Mahapatra, K.. Owners perception on the adoption of building envelope energy ef ficiency measures in Swedish detached houses. Applied Energy 2010;87(7):2411 - 2419.

[26] Asadi, E., da Silva, M.G., Antunes, C.H., Dias, L.. Multi-objective optimization for building retrofit strate gies: A model and an application. Energy and Buildings 2012;44:81 - 87.

[27] Fan, Y., Xia, X.. A multi-objective optimization model for building envelope retrofit planning. Energy Procedia 2015;75:1299 - 1304 .

[28] Olsen, K.H.. The clean development mechanism's contribution to sustainable development: a review of the literature. Climatic Change 2007;84:59-73.

[29] Ye, X., Xia, X., Zhang, J.. Optimal sampling plan for clean development mechanism energy efficiency lighting projects. Applied Energy 2013;

[30] Mondal, A.H., Klein, D.. Impacts of solar home systems on social development in rural Bangladesh. Energy for Sustainable Development 2011;15(1):17 - 20.

[31] Martinot, E., Cabraal, A., Mathur, S.. World Bank/GEF solar home system projects: experiences and lessons learned 1993-2000. Renewable and Sustainable Energy Reviews 2001;5(1):39 - 57.

[32] Ye, X., Xia, X., Zhang, L., Zhu, B.. Optimal maintenance planning for sustainable energy efficiency lighting retrofit projects by a control system approach. Control Engineering Practice 2015;37:1 - 10.

[33] Marion, B., Adelstein, J.. Long-term performance of the SERF PV systems. In: Proceedings of the NCPV and Solar Programme Review Meeting. Denver, Colorado; 2003 .

[34] Laronde, R., Charki, A., Bigaud, D.. Lifetime estimation of a photovoltaic module based on temperature measurement. Solar Energy Engineering 2013;135(2):1-8.

[35] Tazvinga, H., Xia, X., Zhang, J.. Minimum cost solution of photovoltaiccdieselcbattery hybrid power systems for remote consumers. Solar Energy 2013;96:292 - 299.

[36] Tazvinga, H., Zhu, B., Xia, X.. Optimal power flow management for distributed energy resources with batteries. Energy Conversion and Management 2015;102:104 110.
[37] Zhu, B., Tazvinga, H., Xia, X.. Switched model predictive control for energy dispatching of a photovoltaicdiesel-battery hybrid power system. IEEE Transactions on Control Systems Technology 2015;23(3):1229-1236.

[38] Wu, Z., Tazvinga, H., Xia, X.. Demand side management of photovoltaic-battery hybrid system. Applied Energy 2015;148:294 - 304.

[39] Silva, P., Almeida, M., Braganca, L., Mesquita, V.. Methodology to enhance the Portuguese thermal regulation accuracy for existing buildings. In: 11th International IBPSA Conference. Scotland; 2009, p. 576-583.

[40] Suleiman, B.M.. Estimation of U-value of traditional North African houses. Applied Thermal Engineering 2011;31(11-12):1923 - 1928.

[41] Kim, I., de Weck, O.. Adaptive weighted sum method for multiobjective optimization: a new method for pareto front generation. Structural and Multidisciplinary Optimization 2006;31(2):105-116.

[42] Malatji, E.M., Zhang, J., Xia, X.. A multiple objective optimisation model for building energy efficiency investment decision. Energy and Buildings 2013;61:81 - 87 .

[43] South African Bureau of Standards, . Energy efficiency in buildings. Standard; 2011. SANS 204.

[44] Whitley, D.. A genetic algorithm tutorial. Statistics and Computing 1994;4(2):65-85.

[45] Deb, K., Pratap, A., Agarwal, S., Meyarivan, T.. A fast and elitist multiobjective genetic algorithm: NSGAII. IEEE Transactions on Evolutionary Computation 2002;6(2):182-197. 